Research Report No. 46/2013

\title{
Administrative Justice in an Interconnected World
}

Lorne Sossin

Osgoode Hall Law School of York University, lsossin@osgoode.yorku.ca

Follow this and additional works at: http://digitalcommons.osgoode.yorku.ca/clpe

\section{Recommended Citation}

Sossin, Lorne, "Administrative Justice in an Interconnected World" (2013). Comparative Research in Law \& Political Economy. Research Paper No. 46/2013.

http://digitalcommons.osgoode.yorku.ca/clpe/288 


\title{
OSGOODE
}

OSCOODE HALL LAW SCHOOL

YOR K UNIVERSITY

\section{OSGOODE HALL LAW SCHOOL}

Comparative Research in Law \& Political Economy

RESEARCH PAPER SERIES

Research Paper No. 46/2013

\section{Administrative Justice in an Interconnected World}

\author{
Lorne Sossin
}

\section{Editors:}

Peer Zumbansen (Osgoode Hall Law School, Toronto, Director Comparative

Research in Law and Political Economy)

John W. Cioffi (University of California at Riverside)

Comparative Research in Law \& Political Economy 


\title{
ADMINISTRATIVE JUSTICE IN AN INTERCONNECTED WORLD
}

\author{
Dean \& Professor Lorne Sossin*
}

'Administrative Justice in an Interconnected World' is a compelling and elusive topic. Is my goal to discuss the extent to which administrative justice is in fact in an interconnected world or what it would take for this claim to become a reality. The claim that administrative justice is interconnected in this way is the compelling part - in other words, that the many disparate statutory tribunals, boards, agencies, commissions, etc, across the common law world, which exist in a decision-making sphere apart from both courts and government departments, and operate within different legal, political and policy cultures, share enough common ground to constitute a distinct system of justice. The reality is the elusive part - while there are hints at how such interconnected developments might proceed, there are also wholly parallel discussions where administrative law appears to be developing in splendid isolation in each jurisdiction, where legal and policy problems are approached as if no one else had ever considered them, and where occasionally different countries with similar values arrive at disparate responses to the same dilemmas.

While the ambition of administrative justice in an interconnected world is daunting, there is a recurring, intuitive resonance to this proposition. One brief anecdote captures this intuition. Some years back, I was involved in a research initiative commissioned by the Canadian Judicial Council (CJC) on the subject of the models of court administration. While Canada's judiciary has a deserved reputation for excellence, independence and integrity, Canada's courts are managed by executive departments within ministries of justice or offices of Attorneys General. While this created the appearance of conflicts from time to time, given the frequency with which those same government departments appeared before courts, this duality of role was inevitable, so the argument went, because of the inherent constraints of ministerial democracy in a Parliamentary system. Part of our research, of course, involved looking at the state of affairs in other Parliamentary democracies and Australia in particular had a number of courts run on models of judicial autonomy. This ultimately became the recommended model of the CJC, highlighting the Australian experience as a counterpoint to the argument that judicial autonomy was incompatible with ministerial responsibility. Ironically, or perhaps revealingly, when I travelled to Australia to learn the origins of the judicial autonomy model there, many pointed to the inspiration provided by a Report commissioned by the CJC by a Quebec Judge, Jules Deschenes, entitled Masters in Their Own House/Maitres chez eux ${ }^{1}$ - which had found its way to reform minded judges and politicians in Australia. This story, in microcosm, is the porousness I believe informs and enriches the story of the common law in countries like Canada and Australia. Ideas flow in, they flow out, and the sum may well be more than an agglomeration of the parts.

Adjudication in the public interest is an animating principle of administrative justice in all common law jurisdictions. The question is what is particular to a jurisdiction, or a territory, or a cultural and historical perspective? Australia and Canada, for example, both are settler societies with strong indigenous communities where reconciliation and restorative justice are strong themes. Canada, however, also has a strong internal divide that is linguistically and culturally based between French and English Canada which has given rise to a robust form of federalism, 
bilingualism, and bijuralism in law between common law and civil law traditions. Australia, by contrast, lacks this dynamic, but has been shaped by a stronger republican streak than in Canada. Each is predominantly urban and multicultural but whose cultural soul may well reside in the fortitude of a small number of rural and agricultural pioneers overcoming the odds and the elements to build a society. Both countries remain part of the Commonwealth and the Constitutional culture of each was born of an evolution toward federating British colonies, rather than revolutions to assert individual rights or nationalist fervour.

Applying the principles and doctrines of administrative law, and reconciling the intent of legislatures with the lived experience of those seeking justice from these adjudicative bodies, represent broadly shared challenges for administrative justice. This claim also speaks to the very real possibility that developments in one part of the common law world have implications for the other parts. I will attempt to identify the interconnected strands of administrative justice, which will be examined with reference to three areas:

(1) First, I will discuss the foundational issue of the boundaries of administrative law and administrative justice;

(2) Second, I will discuss the interconnectedness of jurisprudence, and will highlight the relationship between Australian and Canadian courts' approaches to the legal standards of fairness; and

(3) Third, I will discuss the interconnectedness of administrative justice through the example of the form and structure of Agencies, Boards and Tribunals, particularly with respect to the wave of accountability concerns sweeping the common law world.

\section{Interconnected questions about administrative law and justice?}

What is administrative law? This should not be as vexing a question as it is. At its core, administrative law provides a framework of accountability for the exercise of executive authority. When considering the judicial review of a statutory decision-maker on grounds the decision was unreasonable or unfair, the question is indeed relatively straight-forward. However, that is where the easy part ends. Here are just a few of the absolutely fundamental questions about the scope of administrative law with which courts both in Australia and Canada have wrestled:

(a) Are administrative tribunals and adjudicative bodies part of the executive or judicial branch of government?

(b) Are there circumstances where a private entity (for example, a company involved in a joint venture with a government agency) is subject to administrative law?

(c) Are any government decisions immune from review on administrative law grounds?

By considering the experience of different common law jurisdictions, it is possible to discern some universal and some particular dynamics. Perhaps surprisingly, the very foundation of the field turns out to be one of the most mutable and changeable issues.

\section{What is administrative justice?}

While the United Kingdom approaches administrative tribunals as a division of the judicial branch of government, both Australia and Canada wrestle with this question. In Canada, tribunals have been held to be part of the executive branch of government, but separated from 
the 'political executive' by a number of common law and in some cases constitutional autonomy protections. In Australia, tribunals appear as neither fish nor fowl, which is what has led some of Australia's leading administrative law thinkers to suggest a fourth branch of government may be necessary to adequately capture the distinctiveness of administrative justice. ${ }^{2}$ Indeed, I have advanced the same argument in the Canadian context. ${ }^{3}$

The scope of administrative justice itself used to be relatively straightforward, flowing from the inherently public nature of a decision-maker authorized to make decisions by statute. However, in the era of public/private partnerships, and public authorities turning to or delegating private providers to deliver publicly funded services (particularly in settings of health care and social benefits but extending to utilities as well as transportation and energy infrastructure). Administrative justice now clearly can extend to private settings.

By contrast, in Canada at least, purely public settings, such as employment relationships between a government agency and public servants, are becoming 'privatized' with respect to legal accountability, as contractual provisions take precedence over doctrines such as procedural fairness. These dual and related trends lead to a blurring of the boundaries of administrative law. Similarly, parties frustrated by the limited remedies and circuitous pathways of administrative justice have turned with growing creativity to the courts - in Canada, for example, bringing class actions on behalf of all taxpayers against a minister for a breach of fiduciary obligations where the minister took a step which appeared to benefit a small group of investors at the expense of the public purse. ${ }^{4}$

\section{What lies beyond administrative justice?}

Should any kinds of public authority lie beyond administrative justice? Justiciability represents one of those universal concepts which each jurisdiction, at least in the common law world, invents for itself. While its periphery can extend to ripeness,mootness and standing, its core relates to two related propositions - first, that some kinds of disputes because of their subject matter are not amenable to judicial determination; and second, that some kinds of disputes, even if amenable to judicial determination, have been assigned to some other form of dispute resolution (for example, disputes over conduct of Parliamentarians has been assigned to the Speaker of the House of Commons rather than the Courts).

Both Australia and Canada can trace their justiciability doctrines relating to prerogative powers as a response to the UK House of Lords 1985 decision in Council of Civil Service Unions. ${ }^{5}$ The case concerned whether consultation was required in relation to the then British PM's decision to prevent unionization of a branch of the security services. The majority of the House of Lords disagreed with the proposition that prerogative powers should remain beyond review. In Canada, while allowing for review of executive authority sourced to prerogative powers generally, a number of areas of such powers have been held non-justiciable on the grounds they are not amenable for judicial determination, including disputes about the conferral of honours in Black ${ }^{6}$ (deciding whether a Canadian citizen should be made a Lord in the UK) and the exercise of foreign relations in Turp $^{7}$ (deciding whether to send troops to Iraq). Australia adopted a similar response in Peko, ${ }^{8}$ where the Australian Federal Court rejected automatic immunity but found a decision relating to declaring part of a park as a heritage site to lie beyond the province of justiciability. 
On the other hand, questions around the core of fairness, bias and independence appear universal. Every common law jurisdiction has struck a remarkably similar balance in this regard but the balance may look quite different, as discussed below.

\section{Interconnected jurisprudence}

Why have Australian Courts embraced the doctrine of legitimate expectations while Canadian Courts have rejected it and instead focused on the interstices of reasonableness and the obligation to provide reasons? Why does rulemaking dominate the administrative law conversation in the US and Europe but not in Australia or Canada, where arguably constraints on executive discretion and standards of review have loomed larger? Asking such questions, in my view, is precisely why approaching administrative justice as interconnectedness is worthwhile. While the discussion below might relate to Canada and Australia, it is a conversation to which every legal jurisdiction will have an important voice to add.

In 1995, the Australian High Court issued its well-known decision in Minister of State for Immigration and Ethnic Affairs $v$ Teoh. ${ }^{9}$ The case concerned Ah Hin Teoh, a Malaysian citizen, who was ordered to be deported after a drug conviction notwithstanding that he and his wife had Australian born children. The majority of the High Court (Mason CJ, Deane, Toohey and Gaudron JJ) agreed with the Federal Court decision that there had been a breach of natural justice as the Immigration department had failed to invite $\mathrm{Mr}$ Teoh to make a submission on whether a deportation order should be made, contrary to the Convention on the Rights of the Child, which provided that in any administrative decision concerning a child, the child's best interests must be a primary consideration. The majority of the Court held that the ratification of an international convention can be a basis for the existence of a legitimate expectation and that, in this instance, there had been a want of procedural fairness.

In 1999, the Supreme Court of Canada synthesized and extended a number of administrative law doctrines in Baker $v$ Canada (Minister of Citizenship and Immigration), ${ }^{10}$ a case dealing with many of the same themes and issues as Teoh. Again, the case arose out of a request to stave off deportation of Mavis Baker, a Jamaican born woman in Canada illegally where she had Canadian born children. The Supreme Court of Canada recognized a duty to provide reasons for the first time in Baker, although the case was decided in Baker's favour because of a breach of fairness based on a reasonable apprehension of bias. The decision of the immigration authorities denying Ms Baker an exemption from the then Immigration Act on humanitarian and compassionate grounds was also quashed on the grounds it was an unreasonable exercise of discretion.

Both Teoh and Baker, decided within a few years of each other, reflected moments of renewed judicial activism in the constraint of executive discretion, and each built on earlier English jurisprudence exploring the principle of legitimate expectations in administrative law. Each has given rise to ripples which washed up on the other jurisdiction's shores, as a number of Australian cases have considered Baker just as a number of Canadian courts have explored the implications of Teoh. Indeed, it is not too far a stretch to conclude through consideration of these cases, that the Australian and Canadian courts together have worked out the dominant common law approach to legitimate expectations.

Baker reached the Federal Court within months of Teoh being released. Justice Strayer who wrote the judgment in Baker on behalf of the Federal Court of Appeal, discussed Teoh at length. He concluded: 
I therefore respectfully reject the reasoning of the majority in the Teoh case and, as did the Motions Judge, adopt the reasoning of McHugh J. The majority judgments in Teoh have been criticized by at least one author. Furthermore, the finding by the Court that Australia's ratification of the Convention amounted to a public undertaking by the government that the Convention would be applied in Australia, thus giving rise to legitimate expectations, was specifically repudiated by that government. $^{11}$

When Baker reached the Supreme Court in Canada, Madam Justice L'Heureux-Dubé, without mentioning Teoh by name, addressed the issue in the following terms:

I turn now to an application of these principles to the circumstances of this case to determine whether the procedures followed respected the duty of procedural fairness. I will first determine whether the duty of procedural fairness that would otherwise be applicable is affected, as the appellant argues, by the existence of a legitimate expectation based upon the text of the articles of the Convention and the fact that Canada has ratified it. In my view, however, the articles of the Convention and their wording did not give rise to a legitimate expectation on the part of Ms Baker that when the decision on her $\mathrm{H} \& \mathrm{C}$ application was made, specific procedural rights above what would normally be required under the duty of fairness would be accorded, a positive finding would be made, or particular criteria would be applied. This Convention is not, in my view, the equivalent of a government representation about how $\mathrm{H} \& \mathrm{C}$ applications will be decided, nor does it suggest that any rights beyond the participatory rights discussed below will be accorded. Therefore, in this case there is no legitimate expectation affecting the content of the duty of fairness, and the fourth factor outlined above therefore does not affect the analysis. It is unnecessary to decide whether an international instrument ratified by Canada could, in other circumstances, give rise to a legitimate expectation. $^{12}$

When the issue next reached the Australian High Court in Re Minister for Immigration and Multicultural Affairs; Ex parte Lam, ${ }^{13}$ the Court specifically considered the approach to the issue which the Supreme Court of Canada had taken in Baker. The case concerned a father with temporary status in Australia once again being separated from his children due to a criminal conviction. The Court addressed Baker in the context of whether legitimate expectations could give rise to substantive as well as procedural remedies:

79. Moreover, the Supreme Court of Canada has stopped short of giving the doctrine of legitimate expectation a substantive operation. Indeed, in Baker v Minister of Citizenship and Immigration, in a judgment with which four other members of the Supreme Court agreed, L'Heureux-Dubé J said: '[T]he doctrine of legitimate expectations cannot lead to substantive rights outside the procedural domain. This doctrine, as applied in Canada, is based on the principle that the 'circumstances' affecting procedural fairness take into account the promises or regular practices of administrative decision-makers, and that it will generally be unfair for them to act in contravention of representations as to procedure, or to backtrack on substantive promises without according significant procedural rights.'

80. The subject was further considered by McLachlin CJ and Binnie $\mathrm{J}$ in their judgment in Mount Sinai Hospital Center v Quebec (Minister of Health and Social Services). Binnie J (who delivered the judgment) discussed Coughlan and continued: 'It thus appears that the English doctrine of legitimate expectation has developed into a comprehensive code that embraces the full gamut of administrative relief from procedural fairness at the low end through "enhanced" procedural fairness based on conduct, thence onwards to estoppel (though it is not to be called that) including substantive relief at the high end, ie the end representing the greatest intrusion by the courts into public administration. The intrusion is said to be justified by the multiplicity of conflicting decisions by a public authority on the same point directed to the same individual(s)'. With the reasoning then developed by Binnie $J$ in the succeeding passages, we would respectfully agree. He writes: 'In ranging over such a vast territory under the banner of "fairness", it is inevitable that subclassifications must be made to differentiate the situations which warrant highly intrusive relief from those which do not. Many of the English cases on legitimate expectations relied on by the respondents, at the low end, would fit comfortably within our principles of procedural fairness. At the high end they represent a level of judicial intervention in government policy that our courts, to date, have considered inappropriate in the absence of a successful challenge under the Canadian 
Charter of Rights and Freedoms. There is, on the one hand, a concern that treating procedural fairness as a subset of legitimate expectations may unnecessarily complicate and indeed inhibit rather than encourage the development of the highly flexible rules of procedural fairness. On the other hand, there is a countervailing concern that using a Minister's prior conduct against him as a launching pad for substantive relief may strike the wrong balance between private and public interests, and blur the role of the court with the role of the Minister.'

Legitimate expectation continues to serve both as a norm of natural justice and as an instantiation of the separation of powers. The result of this interconnected jurisprudence is that the executive branch should be held by the courts to take its promises seriously, but only to the extent that the remedy is fairness. International commitments by the executive matter under this approach, but cannot usurp the role of the legislature in incorporating such commitments into domestic law. Canadian and Australian courts may well have come to this conclusion without reference to the other's judgments, but arguably the analysis of each was enriched by its engagement with the other.

\section{Interconnected structures and standards of administrative justice}

The interconnectedness of administrative law both leads to and is reinforced by the interconnectedness of administrative justice. How are these concepts distinct? Administrative law typically relates to the doctrines which govern administrative decision-making, such as legitimate expectations, discussed above. Administrative justice, by contrast, typically relates to the decision-making structures, whether regulators, tribunals, boards, agencies or ministry departments, and to the lived experience of those who appear before them.

Unlike some of the universal questions addressed above such as 'what is administrative justice?' or 'what is fairness?', the structures of administrative justice are guided by more shifting and particular considerations, such as policy, budgets, patronage and politics. Here too, though, there are interconnecting developments worthy of note. Both Australia and Canada have been witnessing an unprecedented period of experimentation, innovation and change in administrative justice. As in the administrative law context, developments in administrative justice in each jurisdiction have had an interesting and important impact on one another.

The goal of modernizing administrative tribunal systems is ultimately to improve the effectiveness, efficiency, and accessibility of administrative justice - a goal shared across most common law systems. As the costs associated with traditional court-centred legal processes have grown, so has the popularity and variety of administrative tribunals in the view of both policy makers and various user communities. Individuals are looking to these tribunals as simpler and more economical avenues to review administrative decision making and to resolve their disputes, free from the many formal trappings of the law courts - a trend which is likely to continue as the cost of access grows as a concern, not only for socially and economically disadvantaged individuals but also for the politically significant middle class. Similarly, as social and economic disputes become more complex, specialty courts staffed with expert adjudicators often will be more effective than generalist judges.

Unfortunately, even while individual administrative tribunals are promoted as simpler, more efficient and more expert in particular subject matters than courts, fragmentation within tribunal systems continues to thwart these basic dimensions of access for users in several ways. Consider the low-income individual in Ontario who faces a challenge in obtaining social benefits and is in a dispute with her landlord. That individual needs to navigate both the Social Benefits Tribunal and the Landlord Tenant Board's procedures and rules. These two tribunals may 
operate in separate buildings and use different forms. They may employ different styles of adjudication and they may have divergent or even clashing organizational cultures. As a result, the user is forced to navigate a set of institutional silos which impose high financial and informational costs and are likely to impede the overall quality of justice services that the tribunals can offer.

The New Zealand Law Commission has reported a 'lack of overall coherence' in many tribunal systems, making individual tribunals increasingly difficult for users to understand and navigate as interrelated institutions, and vulnerable to claims that they fail to deliver administrative justice in cost-effective ways. ${ }^{14}$ That conclusion echoes earlier comments by Sir Andrew Leggatt in his review of the UK's tribunals:

[m]ost tribunals [in the UK] are entirely self-contained, and operate separately from each other, using different practices and standards. It is obvious that the term 'tribunal system' is a misnomer... each tribunal has evolved as a solution to a particular problem, adapted to one particular area. ${ }^{15}$

One obvious outcome of this fragmented landscape is that the sheer number of administrative tribunals - each with their own physical and logistical infrastructure - represents a considerable duplication of resources and prevents smaller tribunals from achieving economies of scale. In a survey preceding its report on tribunal reform, the New Zealand Law Commission counted over 100 specialist tribunals and courts in that country alone, while Leggatt considered 70 different tribunal bodies within the scope of his review. Despite opportunities for some tribunals to share their resources many remain operating in isolation, probably in part because each tribunal is or perceives itself to be limited by its enabling legislation and by the associated mandates of a particular government ministry. Likewise, individual tribunals are each responsible for designing and implementing their own practices and procedures, making it difficult for users of more than one tribunal to access knowledge and to operate between them. This can be particularly frustrating for users when a single dispute concerns more than one tribunal - for example, where land use, planning and environmental regulatory issues coincide.

Fragmentation arguably hinders first-instance decision-makers from learning more effectively from the decisions of review tribunals. A more coherent system would improve the quality of first-instance decisions by facilitating better feedback processes from tribunal adjudication, allowing judgments from all related tribunals to inform administrative decision making in the future. Certainly, some authors have questioned whether appeal decisions issued by tribunals have traditionally had much effect on the quality of first-instance decision making. Addressing the problems associated with fragmentation in the tribunal system may be one response to this disconnect. Over time, a system that fosters better first-instance decisions will tend to rely less on appeals or judicial review, enhancing access to justice by lowering costs and the time required to achieve a just outcome. Moreover, fragmentation in determining legal rights is likely to make it more difficult for tribunals to maintain decision-making independence from their respective ministries. A system of atomized tribunal bodies operating in relative isolation likely creates more opportunities for departmental capture and makes it difficult to impose and regulate the shared principles of transparency and openness that can flow from greater independence.

System-wide reform efforts in these countries have attempted to address the various aspects of fragmentation that plague modern administrative states. The earliest of these initiatives was to establish the federal Administrative Appeals Tribunal (AAT) in Australia in 1976, following a report by the Commonwealth Administrative Review Committee chaired by Sir John Kerr. At that time, the Kerr Committee sketched a picture of an administrative justice system that was 
uncoordinated, contained many gaps, and was not easily understood by its constituents. The ultimate product of the Committee's report, the Administrative Tribunals Act, created a generalist tribunal to review administrative decisions, which today has jurisdiction to conduct merits review under a wide variety of more than 400 Acts of the federal Parliament.

While a small number of specialist federal tribunals still exist in Australia, the outcome of the AAT model has been to centralize merits review of first-instance decisions within a single organization that includes a membership of appointed judges, lawyers, and experts in various fields such as medical practitioners, engineers and planners. This 'super tribunal' model has been replicated at the State level in Australia, although these tribunals have taken on a variety of different forms in practice. The jurisdiction of the Victoria Civil and Administrative Tribunal (VCAT), for example, extends beyond merits review into human rights and some civil claims. Western Australia's State Administrative Tribunal was not established until 2004 but loosely tracks the structure of the VCAT. Jurisdiction over merits review and dispute settlement in New South Wales remains more fragmented compared to Victoria and Western Australia, although the State's Administrative Decisions Tribunal (ADT), established in 1997, was designed to act in part as an amalgamated generalist review body.

In practice, Peter Cane observes that the new organization of tribunal adjudication in the UK most closely reflects the two-tiered model proposed by Australia's Administrative Research Council in the mid-1990s but later abandoned by the Australian government. ${ }^{16}$ The outcome for the UK, Crane argues, is a system not unlike that of conventional law courts. Australia - at least at the federal level - has so far resisted this trajectory in favour of a model that sees amalgamated tribunal agencies as a 'distinct genus of adjudicatory institution' that seek to maintain their pragmatic advantages in terms of speed, affordability and informality.

At root, each of these responses can be understood as attempts to re-imagine individual tribunals as part of a coherent and continuous system of administrative justice. That perspective took longer to catch hold in Canada. According to Heather McNaughton, '[i]t was not until recently that governments and Canadian courts have started to conceptualize administrative tribunals dealing with such disparate interests as the protection of fundamental human rights, the issuance and transfer of quota for production of agricultural products, and property tax assessment, as being part of a system of justice. ${ }^{17}$ Michael Adler has labeled this an 'administrative justice approach' which recognizes the important role of courts, tribunals, ombudsmen and other external redress mechanisms but also emphasizes internal means of enhancing administrative decisions such as recruitment, training and appraisal processes, as well as standard setting and quality assurance systems. ${ }^{18}$

A countervailing consideration to whole system reform is that administrative tribunals must retain a degree of flexibility in order to accommodate and support their particular mandates and areas of expertise. McNaughton cautions that ' $[\mathrm{t}$ ]he temptation to one size fits all reforms fails to take into account the fact that the specialist areas delegated to administrative tribunals form the very basis for their existence in the first place.' The main challenge of tribunal reform might thus be seen as an attempt to modernize and rationalize administrative tribunal systems while respecting, maintaining and promoting core principles of accessibility, pragmatism, and expediency. In other words, the key is to make the system coherent while keeping it 'nimble'.

In 2009, Ontario adopted the Adjudicative Tribunals Accountability, Governance and Appointments Act (ATAAGA) which established a mechanism for creating Tribunal clusters. ${ }^{19}$ Clusters bring together distinct tribunals which share a subject area theme, and allow those 
tribunals to harness shared services, standards and locales as well as cross-appointments and joint training. Using that legislation, the Ontario Government has created two clusters thus far the Environmental \& Land Tribunal of Ontario (ELTO), which is made up of four separate tribunals, and the Social Justice Tribunal of Ontario (SJTO), which has seven distinct tribunals. The clustering concept drew express inspiration from the Australian context, just as the proposed New South Wales Civil and Administrative Tribunal (NCAT), which seeks to consolidate a wide range of tribunals but preserve their distinct areas of expertise seems to be a potential alternative to clustering (the NCAT is set to launch in 2014 with five specialty divisions - Consumer, Administrative and Equal Opportunity, Occupational and Regulatory, Guardianship, and Victims).

Just as clusters and super-tribunals have arisen as a structure for administrative justice, new legislation in Ontario and elsewhere in Canada has focused on the accountability of administrative justice. ATAAGA has for the first time required all tribunals to have codes of conduct addressing conflicts of interest and publicly available business plans, and memoranda of understanding with the government outlining roles and responsibilities of the Government and quasi-independent adjudicative bodies. More so than the specific changes to which this legislation may lead, the creation of coherent templates for this accountability contributes to the reality of an administrative justice system rather than a disparate and uncoordinated set of agencies, boards and tribunals.

Accountability also has been a driver of administrative justice in Australia. For example, COAT's 2012 'Framework of Excellence' seeks to provide an evidence based approach to the evaluation of tribunal performance (which builds on a 2008 Framework of Excellence applicable to courts). ${ }^{20}$ The Framework focuses on the core values of tribunals, the areas of excellence and the criteria for measuring excellence. Last summer, I received an email from the Chair of the SJTO cluster asking if I had come across the Framework and how it might speak to the Canadian experience with administrative justice. In the case of administrative justice, it is not just judges who have been creating the interconnectedness of administrative law jurisprudence, but tribunal members themselves. While the optimal structure of a tribunal may not be a universal question, how to measure the success of an administrative or adjudicative decision is. Should success be determined based on the satisfaction of the parties, the degree of public confidence which a decision-making body enjoys or other quantitative measures (volume of caseload, cost, delay, etc)?

The Framework of Excellence may not be a universally applicable standard, but it has sparked meaningful debate in many jurisdictions about the goals of administrative justice and the appropriate forms of accountability to which administrative decision-makers should be subject. Interconnectedness, in this sense, is not about one development in a jurisdiction affecting other jurisdictions but rather about a shared conversation.

\section{Conclusion}

This brings me to the conclusion of this brief analysis. I hope I have illustrated both the ways in which the interconnectedness of administrative justice is a claim and a reality. I would suggest, in light of the above discussion, that interconnectedness in administrative law flows from three key conditions: 
(1) first, the presence of a question that is widely applicable to diverse jurisdictions, such as the scope of fairness, or the separation of powers between executive, legislative and judicial action.;

(2) second, the presence of particular answers in distinct jurisdictions which differ sufficiently to require an explanation, such as the legitimate expectations/reasonableness divergence arising out of Teoh and Baker; and

(3) third, a venue or venues for shared conversations about administrative justice, such as the connections, blog posts and conference chats that led to the 'Framework of Excellence' migrating from Australia to Canada last summer.

Where these three conditions are present, as in the areas explored above, administrative justice operates on two levels simultaneously - both as a body of doctrines and principles within a particular jurisdiction and as a body of doctrines and principles developing across jurisdictions. The nature, scope and dynamics of this latter sense of administrative justice remain embryonic. I hope this broader lens on administrative justice continues to come into focus, and that the conversation about the interconnectedness of administrative justice continues to spark critique and innovation by allowing us to see our own adjudicative bodies and political/legal cultures in a new light.

*Professor Lorne Sossin is Dean Osgoode Hall Law School, York University, Toronto, Ontario, Canada. This paper was the keynote address at the 2013 AIAL Australian National Administrative Law Conference, Canberra, 18 July 2013.

\footnotetext{
${ }^{1}$ Maîtres chez eux/Masters in their own House, was a study prepared by Mr Justice Jules Deschênes and sponsored by the Canadian Judicial Council, dated September 1981.

${ }^{2}$ See Robin Creyke, 'Administrative Justice: Towards Integrity in Government' (2007) 31 Melbourne University Law Review 705.

${ }^{3} \mathrm{~L}$ Sossin, 'The Ambivalence of Administrative Justice in Canada: Does Canada Need a Fourth Branch?' in Lamer: The Sacred Fire, D Jutras and A Dodek (eds) (2009) 46 Supreme Court Law Review 51.

${ }^{4} \mathrm{~L}$ Sossin, 'Revisiting Class Actions Against the Crown: Balancing Public and Private Legal Accountability for Government Action' in J Kalajdzic (ed), Accessing Justice (Toronto: LexisNexis, 2011), pp 31-48.

${ }^{5}$ Council of Civil Service Unions v Minister for the Civil Service [1985] AC 374.

${ }^{6}$ Black v Chrétien (2001), 54 O.R. (3d) 215 (CA).

7 Turp et al. v Chrétien, McCallum, Graham and Cauchon, 2003 FCT 301.

${ }^{8}$ Peko-Wallsend (1987) 15 FCR 274.

9 Minister of State for Immigration and Ethnic Affairs v Teoh (1995) 128 ALR 353.

${ }^{10}$ [1999] 2 SCR 819.

11 [1997] 2 FC 127.

12 Supra para. 29.

13 [2003] HCA 6.

${ }^{14}$ New Zealand Law Commission, Tribunal Reform (New Zealand Law Commission SP 20, 2008) http://www.lawcom.govt.nz/sites/default/files/publications/2008/12/Publication_131_424_Web\%20Tribunal-ReformStudy-Paper-20.pdf.

${ }^{15}$ Andrew Leggatt, Tribunals for Users: One System, One Service (Stationery Office 2001) at http://webarchive.nationalarchives.gov.uk/+/http:/www.tribunals-review.org.uk/leggatthtm/leg-00.htm.

${ }^{16}$ Peter Cane, Administrative Tribunals and Adjudication (Hart Publishing, 2009). See also Peter Cane, 'Judicial Review in the Age of Tribunals' (2009) Public Law 479.

${ }^{17}$ Heather MacNaughton, 'Future Directions for Administrative Tribunals: Canadian Administrative Justice - Where do we go from Here?' in Robin Creyke (ed), Tribunals in the Common Law World (Federation Press, 2008).
} 
${ }^{18}$ Michael Adler, 'Understanding and Analyzing Administrative Justice' in Michael Adler (ed), Administrative Justice in Context (Hart, 2010)145.

${ }^{19}$ For a discussion of Ontario's tribunal clusters, see L Sossin and J Baxter, 'Ontario's Administrative Tribunal Clusters: A Glass Half-Full or Half-Empty for Administrative Justice' (2012) 12 Oxford Commonwealth Law Journal 157.

${ }^{20}$ At:

http://www.coat.gov.au/sites/default/files/docs/international_framework_for_tribunal_excellence_november_2012.pdf. 